\title{
Smart Dust Bin for Waste Management
}

\author{
Nyamatulla M Patel ${ }^{1}$, Balesh Nander ${ }^{2}$ Sankalp Patil ${ }^{3}$ \\ ${ }^{I}$ Asst. Prof. Dept. of CSE, Hirasugar Institute of Technology, Nidasoshi, Belagavi, Karnataka \\ ${ }^{2}$ Students Dept. of ECE, Hirasugar Institute of Technology, Nidasoshi, Belagavi, Karnataka \\ ${ }^{3}$ Students Dept. of ECE, Hirasugar Institute of Technology, Nidasoshi, Belagavi, Karnataka \\ ${ }^{1}$ nmpatel.ece@hsit.ac.in \\ ${ }^{2}$ baleshnander7@gmail.com \\ ${ }^{3}$ patilsankalp@gmail.com
}

\begin{abstract}
In recent decades Urbanization is increased tremendously. At the same phase there is an increase in waste production. These days managing the waste has become very important issue to be considered for keeping the city clean. The system is built on Arduino board which is connected with GSM modem and Ultrasonic sensor for waste management.
\end{abstract}

The smart waste bin can be used to keep the city clean. The system is built such that it can measure the weight and amount waste in bin, also adapt with network environment, to manage all information from waste management to the municipality so that we can keep the city clean.

Keywords - Arduino Uno, IDE, MQ5 sensor, Ultrasonic sensor, ATmega328P.

\section{INTRODUCTION}

These days' cities are too much crowded; to keep the city clean intelligent bin can be to monitor the amount waste present in the bins. This system monitors the bins and informs about the level of garbage present in the garbage bins using IOT. Ultrasonic sensor is used to measure the level of garbage in the bins. AVR family based microcontroller is used in the system. Wi-Fi modem is used for sending data and uses a buzzer to generate the beep when the bin is full. The system requires a power of $12 \mathrm{~V}$ to work. To keep the information about the status of bin a LCD screen is used.

Arduino Uno is the heart of complete system. All the components are mentored by this. DC supply is required to keep the system working. Ultrasonic sensors are used to check whether the bins are full or below the threshold level. The information regarding the bins is sent from ultrasonic sensor to Arduino, then based the data received the information regarding the bins is displayed on the LCD screen.

\section{LITERATURE SURVEY}

[1] Healthy environment is imperative to a healthy and happy community. The old method of manually monitoring the bins will lead to lot of human errors. In some areas the bins are more frequently used while other areas they are used less, because of this bins will overflow and waste may over the bin and will become the source of many decreases. Lot of human effort is wasted and even the system will be more expensive.

[2] The tremendous growth in urbanization and mushrooming of the smart cities all over the world has increased the amount of wastes produced in an alarming rate. The garbage management is thus one of the crucial issues to be considered. The advancements in the technology, and the growth of the sensational gizmo Internet of Things provided a pervasive touch to all the things around. The paper is an extensive survey on smart garbage management systems. The garbage monitoring, segregation, transportation and disposal techniques are studied and compared. Finally an integrated system that involves the monitoring of garbage levels using sensor technology, route optimization of the trucks by using efficient algorithms, automated segregation systems that separates biodegradable and non-biodegradable wastes and smart disposal techniques is developed. The ultrasonic proximity sensor, inductive sensor, capacitance sensor, raspberry pi, GSM technology and artificial intelligence are used to monitor, segregate and dispose wastes.

\section{SYSTEM DESIGN}

The aim of this system is to monitor the bins remotely. Bluetooth is used in the data transmission side. Bluetooth sends data wirelessly and the best method of remotely controlling the devices and send data and it is suitable for operation in harsh environments and in isolated locations. The main problem with Bluetooth is that it can cover very small distance. Therefore, in this system GSM is used. A 


\section{International Journal of Engineering Technology and Management Sciences[IJETMSS]}

Website: ijetms.in Issue:5, Volume No.4, September-2020 DOI: 10.46647/ijetms.2020.v04i05.001

GSM works with works with a GSM wireless network. It uses a SIM card and just works like a cell phone for sending the information.

The smart dust bin has a transmitter section. This section consists of four IR sensors, placed at different level along the bust bin. The function of these IR sensors is to detect the level of garbage present in the bin and keep informing the system about the status of the bin. When the garbage level reaches the last IR sensor, it informs the control room that a particular bin is filled and need an

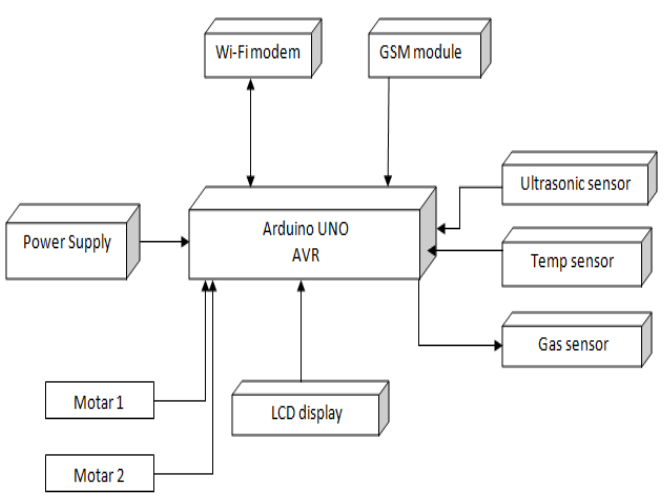

immediate action. Then system takes appropriate action.

Fig.01: Block diagram for smart dust bin for waste management.

\section{COMPONENTS USED}

\section{A. Arduino Uno board}

Atmega328P comes with 14I/O pins, out of 14 pins, 6 pins give PWM output, 6 are analog inputs. The controller has a $16 \mathrm{MHz}$ quartz oscillator, its USB connection and power supply point; it also has ICSP and reset option. Everything that is required for system to work is present on the board. Using the USB option the controller can be powered on.

Arduino Uno uses Arduino software for programming the controller using appropriate code. The Arduino board is most preferred for the development of many IOT based applications. Looking at the advantages of Arduino in this system the same board is used for design of the system.

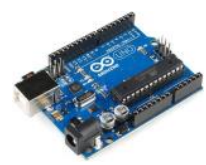

Fig.02: ATmega328P

\section{B. Potentiometer}

The designed system contains adjustable resistor called as potentiometer. Based on the system requirement the

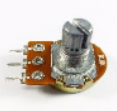

potentiometer can be adjusted so that the systems work properly and give desired results. Using the potentiometer the desired level output level can be set.

Fig.03: Potentiometer

\section{Ultrasonic sensor}

The ultrasonic sensor is used to find the object which comes in its path, it works by sending the signal is a particular direction, if an object is found along its path its sends the information to the controller to take appropriate action and controls the bin from overflowing.

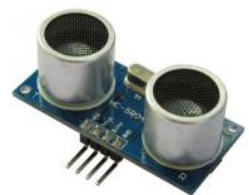

Fig.04: Ultrasonic Sensor

\section{Buzzer}

The system uses a Peizo-buzzer to produce a alarm when the bin is full and informs the control room that a bin is full and needs appropriate action. The buzzer used in this system works in the frequency range from 2 to $4 \mathrm{KHz}$ and works on principle of piezoelectric effect.

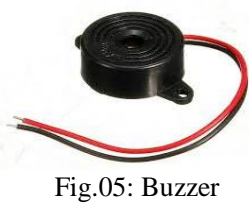

\section{E. LCD display}

The LCD display can be interfaced to the system in either 4 bit or 8 bit data interface length mode but we have selected an 8 bit interface mode for faster display data update. The previous mode could be used in applications where the number of I/O pins availability is limited i.e. A smaller MCU with less I/O Pins. The LCD is interfaced to the MCU with data lines connected to port 1 of the 8051 and control lines RS, EN connected to port 3.2, 3.3 


\section{International Journal of Engineering Technology and Management Sciences[IJETMSS]}

Website: ijetms.in Issue:5, Volume No.4, September-2020 DOI: 10.46647/ijetms.2020.v04i05.001

respectively. The $\mathrm{R} / \mathrm{W}$ control line is permanently tied to ground for write only operations to the LCD display produced and also a buzzer is enabled for alarming against a wet floor.

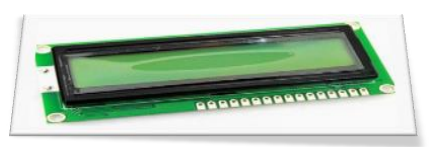

Fig.06: LCD display

\section{F. GSM Module}

The GSM module is used in the system for sending and receiving text messages the text messaging service of the GSM network service provider is used to change settings of the system as incoming messages, and to generate alerts as outgoing messages, also the system will make outgoing calls to stored numbers in case of alerts. The GSM module used is a type M10 from Quectel Wireless Corporation. The GSM module is interfaced to the UART of the MCU and uses AT commands for its operation.

The GSM Module used in the system is very reliable and small is size, it supports dual band GSM/GPRS in SMT structure which can be installed in different applications because of its dimensions and less cost.

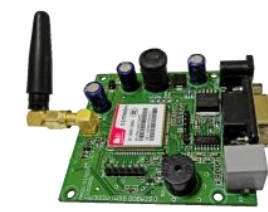

Fig.07: GSM SIM900A

\section{G. Wi-Fi Module}

In this system a Wi-Fi component is used which is a complete system on chip, the ESP8266 module is a Wi-Fi component used in the system which works on TCP/IP protocol and can be easily connected to microcontroller to access the network. The ESP8266 is able host an application or it can perform all networking functions from other application. ESP8266 is a pre-programmed device with an AT firmware. The cost if this component is very less and is widely used; this is capable of performing onboard processing and has storage capability. Using GPIO pins many sensors and other application specific devices can be easily connected with minimum effort and less runtime.

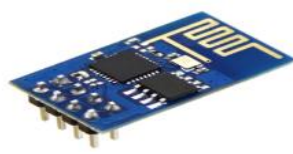

Fig.08: Wi-Fi Module ESP8266

\section{H. Gas Sensor}

MQ5 Gas sensor which is a generic Gas Sensor more suited to detect and determine LPG concentrations with Arduino. This module has two output possibilities - an analog out (A0) and a digital out (D0). The leakage of gas and to measure volume of gas leakage the analog output is used by performing proper calculations and it gives the result in PPM by executing a program part present in the system. If gas leakage is more than the digital output is used to generate the alarm or to send an SMS. The digital out gives only two possible outputs High and Low hence it's more suited for detection of gas leak than to measure volume of gas presence.

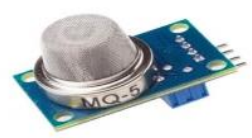

Fig.09: MQ5 Gas Sensor

\section{Temperature sensor}

The LM35 is a temperature sensor which gives output temperature in centigrade. This device is very effective as compared to others, as its gives correct value of temperature without performing any other calculations. This device does not require any calibration and provides accurate results from $-55^{\circ} \mathrm{C}$ TO $150^{\circ} \mathrm{C}$ range; this device has very less output impedance and precision and can be easily connected.

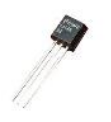

Fig.10: LM35

\section{RESULT ANALYSIS AND DISCUSSION}

Based on the experimental analysis it is clear that the system designed for smart management of waste in cities works well and is efficient. This model helps to keep city clean and prevents occurrence of many deceases and bad 


\section{International Journal of Engineering Technology and Management Sciences[IJETMS]}

Website: ijetms.in Issue:5, Volume No.4, September-2020 DOI: 10.46647/ijetms.2020.v04i05.001

odor. The system designed better compared to other models developed so far with an overall efficiency of $98 \%$.

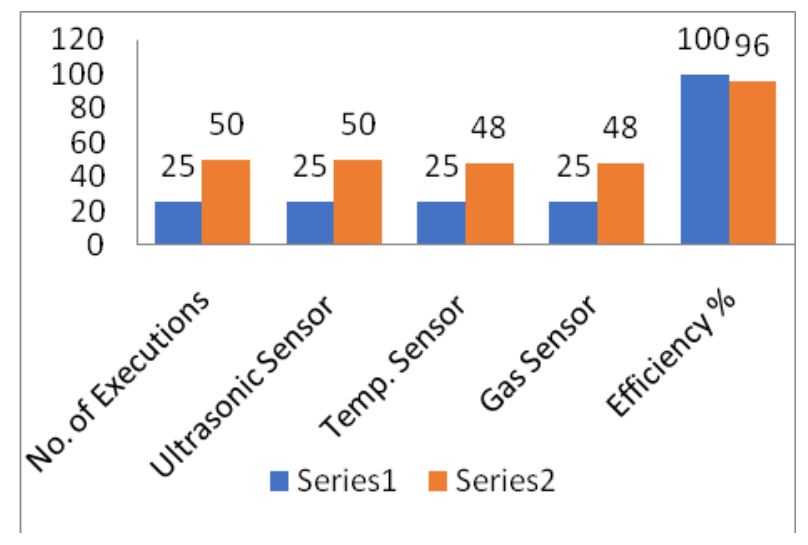

Fig.11: Graph showing system efficiency \& performance.

\section{CONCLUSIONS}

The project developed works well and sends information to the concern people regarding the status of bin. As the garbage bin is cleaned regularly, so there is no chance of generation of bacterial, which helps in avoiding many diseases. As the system developed is based on IOT, so it can be operated and managed without much complexity. From the result analysis and tests conducted in system it is clear that the developed system works well, and it is effective with an efficiency of $98 \%$.

\section{References}

[1].Ghose, M. K. Dikshit, A. K Sharma, S.K. A case study on Alanson municipality Journal of Waste Management, A GIS based transportation model for solid waste disposal.

[2].Guerrero, L. A. Maas, G. Hogland, - Solid waste management challenges for cities in developing countries. Journal of Waste Management.

[3].Kasliwal Manish, Suryawanshi Smitkumar B, -A Novel Approach to Garbage Management Using Internet of Things for Smart Citiesll.

[4].Meghan K C, Dr. K R Nataraj, IOT Based Intelligent Bin for Smart Cities.

\begin{abstract}
About Author
Mr. Nyamatulla M Patel, Assistant Professor, Hirasugar Institute of Technology, Nidasoshi, having 15years of experience in teaching. Areas of interest embedded systems, IOT, Image Processing.
\end{abstract}

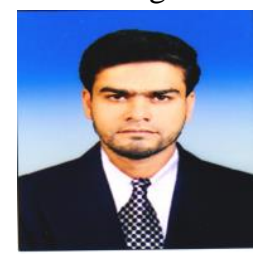

